\title{
In Silico Analysis of Tumor Necrosis Factor (TNF) in Homo sapiens
}

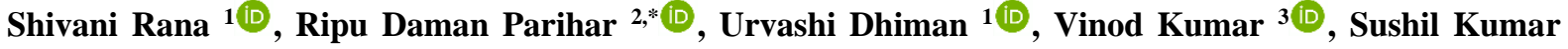 \\ Upadhyay 4 (D) \\ Department of Zoology, DAV University, Jalandhar, India \\ Department of Zoology, University of Jammu, Jammu \& Kashmir, India \\ Department of Botany, Government Degree College Ramban, Jammu \& Kashmir, India \\ Department of Biotechnology, Maharishi Markandeshwar (Deemed to be University), Mullana-Ambala-133207 \\ (Haryana), India \\ * Correspondence: ripuparihar89@gmail.com;
}

Scopus Author ID 56692536400

Received: 20.02.2021; Revised: 29.03.2021; Accepted: 5.04.2021; Published: 26.04.2021

\begin{abstract}
Tumor Necrosis Factor (TNF) encodes a pleiotropic proinflammatory cytokine that plays a major role in regulating immune cells. The cytokine involved the perception of a wide spectrum of biological processes, including cell proliferation, differentiation, apoptosis, lipid metabolism, and coagulation. It has also been implicated in various diseases such as autoimmune disorders, insulin resistance, cancer, etc. Considering the in-depth significance of TNF, the present study was designed for their in silico analysis in Homo sapiens. This study is undertaken to find the functional and structural basis of TNF in H. sapiens, by using various bioinformatics tools. In silico evaluation of these proteins includes physicochemical parameters, prediction of secondary structures, and validation of different models. These proteins could be directly or indirectly stabilized by the amino acid interactions and hydrogen-bond networks. It elucidated the functional deviations of protein to some extent and laid the foundation for docking and molecular modeling for future prospects.
\end{abstract}

Keywords: tumor necrosis factor; Homo sapiens; physiochemical parameters; cytokines; molecular modeling.

Abbreviations: TNF: Tumor Necrosis Factor, ExPasy: Expert Protein Analysis System, TNFSF: Tumor Necrosis Factor Superfamily, NCBI: National Centre for Biotechnology Information, SOPMA: Self-Optimized Prediction Method with Alignment, RAMPAGE: RNA Annotation and Mapping of Promoters for the Analysis of Gene Expression, I-TASSER: Iterative Threading Assembly Refinement, MEGA: Molecular Evolutionary Genetic Analysis, TNFRSM: Tumor Necrosis Factor Receptor Superfamily Member, SLE : Systemic Lupus Erythematosus.

(C) 2021 by the authors. This article is an open-access article distributed under the terms and conditions of the Creative Commons Attribution (CC BY) license (https://creativecommons.org/licenses/by/4.0/).

\section{Introduction}

Tumor Necrosis Factor (TNF) is a multifunctional proinflammatory cytokine, mainly secreted by macrophages during acute inflammation and is responsible for a diverse range of signaling events within the cells $[1,2]$. TNF alpha is involved in different pathways like proliferation, migration, survival, differentiation, and various inflammatory diseases [3-6]. The interaction between TNF and its receptors initiates the complex molecular pathways, which lead to death and inflammation of cells [7]. TNF is an inflammatory cytokine involved in the pathology of various diseases of humans. Long-term anti-TNF therapy has proven to be beneficial for normal physiological activities [8]. It has been revealed that TNF alpha 
polymorphism may be concerned with increase susceptibility to PTB (pulmonary tuberculosis), migraine, metabolic syndrome, and sepsis [9-12]. TNF was identified as an Endotoxin-induced serum factor responsible for causing the necrosis of many tumors [13]. During tumor formation, the TNF- $\alpha$ helps regulate immune cell processes, MMP-9, and integrin $\alpha v \beta 6$ [14]. It helps in the activation of cytokines and different agents [15]. Inhibitory TNF drugs are used to treat rheumatologic diseases, NSCLC (non-small cell lung cancer), and other cancers [16]. $\mathrm{TNF} \alpha$ works by binding as a trimer to either $55 \mathrm{KDa}$ cell membrane receptor (TNFR-1) or $75 \mathrm{KDa}$ cell membrane receptor (TNFR-2), which is receptors of TNF receptor superfamily and initiates the various signaling/protein cascades [1,17]. These protein cascades are serine/threonine kinases responsible for the activation of MAP and Jun kinase and cause the activation of $\mathrm{NF}_{\mathrm{k}} \mathrm{B}$ transcription factor [18]. The function of $\mathrm{NF}_{\mathrm{k}} \mathrm{B}$ is to control the production of several proinflammatory cytokines such as TNF- $\alpha$ and certain associated proteins that are conspicuous for immuno-inflammatory diseases [19]. It has been concluded that in both TNF $\alpha$ and $\mathrm{NF}_{\mathrm{k}} \mathrm{B}$, the expression levels are managed by a similar feedback loop [20]. Studies have been found that TNF alpha downregulates the IRF7, IFN- $\alpha$, inflammatory signaling pathways, and NF-kB pathways by upregulating the T-cell activation and TNF production in human plamocytoid dendritic cells [21,22].

TNF $\alpha$ Induced Protein 8 (TNFAIP8) is the earliest discovered component of TNFAIP8 family. It contains putative Death Effective Domain, which is the same as DEDII in FLIP (FasAssociated death domain-like interleukin-1 $\beta$ converting enzyme inhibitory protein). It may affect cell survival and the death process. It also inhibits apoptosis and autophagy in various cells. TNFAIP8 might be an anti-apoptotic and oncogenetic protein whose level fluctuates in patients having inflammatory, malignant and autoimmune diseases [23]. TNFAIP8 is responsible for causing various cancers, including cancer of the prostate, liver, lung, breast, colon, esophagus, ovary, and others. TNFAIP8 inhibits cell apoptosis in human cancer and promotes cell proliferation, invasion, metastasis, drug resistance, autophagy, and tumorigenesis [24]. TNF $\alpha$ is considered potent proinflammatory and pathological cytokines in inflammatory diseases like rheumatoid arthritis, SLE, and inflammatory bowel diseases [25-26]. For better control over diseases, TNF alpha can be induced from Mtlb Esxl by using Toll-Like Receptor (TLR2) through activation of nuclear factor-kB and MAPK signaling [27]. TNF $\alpha$ is also involved in developing insulin resistance and pathogenesis of T2DM (Type 2 Diabetes Mellitus) [28]. TNF alpha also plays a harmful and antagonistic role in the heart's physiopathology, which includes cardioprotective action against ischemia, reperfusion injury, and heart failure [29]. Studies have also confirmed a significant correlation between TNFalphafactor and cognitive scores in Multiple Sclerosis patients [30].

TNF plays a significant role in inflammation, and neuronal degeneration, despite this, Anti-TNF therapeutics are failed to treat neurodegenerative disease. Studies of animal disease models showed that two TNF receptors had contradictory effects on the central nervous system (CNS), in which TNFR1 has a role in inflammatory degeneration while TNFR2 is associated with neuroprotection. Inhibition of TNFR 1 and activation of TNFR 2 by ATROSAB in a mouse model of NMDA may induce acute neurodegeneration, but continuous blocking of TNFR1 and TNFR2 signaling may prohibit their therapeutic effect. The therapeutic activity of ATROSAB, which is mediated by the prohibited activity of TNF toward TNFR2, proven to be essential for neuroprotection. Studies also reveal that the complete blocking of TNF activity by anti-TNF drugs was harmful rather than protective, despite the use of next-generation TNFR2 selective TNF therapeutics, which are effective in treating neurodegenerative diseases [31]. Increased 
cervical cancer level is associated with genetic transformation in the TNF alpha gene and induces a distress component for cervical neoplasia [32]. Conclusions proved that to decrease the effect of sympathetic hyperreflexia, signaling of TNF alpha must be inhibited before two weeks of SCI (spinal cord injury). TNF alpha actively participates in metastasis and cancer distension $[33,34]$. Various essential oils extracted from plants have been proven effective inhibitors for cytokine tumor necrosis factor-alpha and many other diseases [35]. TNF alpha and TNFSF (tumor necrosis factor superfamily) are directly related to phosphorus, CKD-MBD (chronic kidney disease-mineral bone disorder) by contributing to its growth and inversely related with height $\mathrm{z}$ - score [36]. The transcriptional activation of TNF $\alpha$ is responsible for various inflammatory and malignant diseases [37]. The increased level of TNF activates the NK cells, mitochondrial dysfunction, and also increases the chances of hypertension and fetal abnormalities during pregnancy[38]. Inhibition of TNF alpha is directly related to the suppression of TIN (tubulointerstitial injury) in diabetic rats [39]. Studies reveal that proinflammatory markers like IL-6 (Interleukin 6) and TNF $\alpha$ are highly articulated in degenerated human intervertebral discs [40]. The prohibition of transcriptional functions of TNF $\alpha$ accounts for an efficacious therapeutic perspective for the control of diseases.

On the contrary, an increased level of mRNA in TNF $\alpha$ has been found in severe asthma cases [41]. Thus the prohibition of TNF $\alpha$ could be a helpful target for the quest for antiasthmatics medicines [42]. However, various TNF $\alpha$ antagonists have been already licensed by the Food and Drug Administration and are available in the market, for example, Infliximab, golimumab, adalimumab, and certolizumab [43]. But the cost of medicines for people in different developing countries is very high and out of their reach. Thus the economic development of molecular inhibitors of tumor necrosis factor is very important, and for this, one should have information about TNF structures [44]. Even the knowledge about the threedimensional structures, amino acid composition, and counter constitution of protein is crucial for designing new or unusual inhibitors that can take the place of medicines. In this study, bioinformatics analysis has been performed on physiochemical properties of TNF to elucidate the functional deviations of TNF to some extent. Nematode Caenorhabditis elegans has been used for many TNF studies besides cell lines [45]. Recently, Distollabrellus veechi has been used as a living model to study the activity of fluorescent compounds [46-51]. In silico studies of TNF can be used to explore future prospects in this dimension also.

\section{Materials and Methods}

\subsection{Collection of data/retrieval of amino acid sequences.}

The National Centre for Biotechnology (NCBI) is one of the world's leading networks for computational and biomedical research and was used to retrieve amino acid sequences or FASTA files for our work (https://www.ncbi.nlm.nih.gov/). A total of ten proteins and their sequences in FASTA format were fetched (Table 1).

\subsection{Primary structure prediction and physico-chemical characterization.}

PROTPARAM ExPasy (Expert Protein Analysis System) was utilized for primary design expectation and examination of different physical and compound properties of protein sequences. The analyzed factors included atomic weight, hypothetical pI, amino acid composition, i.e., number of positively and negatively charged amino acids, instability index, 
and so on. An investigation of physicochemical boundaries is significant in describing the job of protein and its atomic advancement [52].

Table 1. Various genes with their accession numbers were used for the study.

\begin{tabular}{l|l} 
Protein Name & Accession Number (NCBI) \\
\hline TNF & NP_000585 \\
\hline TNFRSM 21 PRECURSOR & NP_055267 \\
\hline TNFRSM 6B PRECURSOR & NP_003814 \\
\hline TNFRSM 18 ISOFORM 2 PRECURSORS & NP_683699 \\
\hline TNFRSM 1A ISOFORM 1 & NP_001056 \\
\hline TNFRSM 1A ISOFORM 2 & NP_001333020 \\
\hline TNFRSM 1A ISOFORM 3 & NP_001333021 \\
\hline TNFR LIGAND SM 13 ISOFORM $\alpha$ PRECURSOR & NP_003799
\end{tabular}

\subsection{Secondary structure prediction.}

A tool called SOPMA (Self- Optimized Prediction Method with Alignment) was used to evaluate the secondary structure of proteins. SOPMA evaluates parameters like alpha-helix percentage, beta-sheet turns, extended strands, random coils, etc. [53].

\section{4. $3 D$ structure prediction.}

I-TASSER (Iterative Threading Assembly Refinement) was used to provide the automated full-length 3D protein structures, which help obtain quantitative models [54]. The server is freely available, and for a single protein, the tool generates five full-length models [55].

\subsection{Validation of generated models.}

Five full-length models provided via I-TASSER were again evaluated by different bioinformatics tools like ERRAT, 3D-VERIFY, PROCHECK, and RAMPAGE.

\subsubsection{D-Verify.}

The 3D profile of a protein structure is data from the atomic coordinates of the structures used to score the compatibility of amino acid sequences with 3D structures (http://servicesn.mbi.ucla.edu/Verify3D/). It is also useful in evaluating undetermined protein models, which are based on electron density maps or computational procedures $[56,57]$.

\subsubsection{Errat.}

It helps in model building or in checking structures. It is a program for verifying protein structures determined by crystallography. Error-values are plotted as a function of a sliding 9 residue window (http://omictools.com/errat-tool) [58].

\subsubsection{Rampage.}

RAMPAGE (RNA Annotation and Mapping of Promoters for the Analysis of Gene Expression) will give a nitty-gritty design assessment through the Ramachandran plot. (http://mordred.bioc.cam.ac.uk/ rapper/rampage.php) [59]. 


\subsubsection{Procheck.}

It provides a detailed check on the stereochemistry of a protein structure (http://www.ebi.ac.uk/thorntonsrv/databases/pdbsum/Generate.html) and assesses the overall quality of the structures as compared with refined structures of the same resolution. This is also useful for checking the quality of not only protein structures that are in process but also existing structures [60]. The tool's results include plots, information about residues present in outlier and favored regions [61].

\subsection{Phylogenetic analysis.}

For the construction of evolutionary relationships and analyzing genomic data Molecular Evolutionary Genetic Analysis (MEGA) was used [62].

\subsection{Statistical analysis.}

To correlate different amino acids in the proteins, Pearson correlation and Multivariate techniques were used.

\section{Results and Discussion}

Protparam tool from ExPasy was used to analyze physicochemical properties of Tumor Necrosis Factor in H. sapiens (Tables 2,3). These protein's determined properties play an important role in analyzing the stability and sustainability of a protein in a biological system [63]. Among tumor necrosis genes of $H$. sapiens TNFRSM21 showed the highest molecular weight, i.e., 71844.86 KDa, and TNF showed the lowest molecular weight, i.e., 25644.42KDa (Table 3). Similar to our study, in silico studies have been reported in Caenorhabditis elegans and Photorhabdus temperata [64].

Table 2. Amino acid (\%) of Tumor Necrosis Factor in Homo sapiens.

\begin{tabular}{l|l|l|l|l|l|l|l|l|l|l|l|l|l|l|l|l|l|l|l|l} 
Proteins & $\mathbf{A}$ & $\mathbf{R}$ & $\mathbf{N}$ & $\mathbf{D}$ & $\mathbf{C}$ & $\mathbf{Q}$ & $\mathbf{E}$ & $\mathbf{G}$ & $\mathbf{H}$ & $\mathbf{I}$ & $\mathbf{L}$ & $\mathbf{K}$ & $\mathbf{M}$ & $\mathbf{F}$ & $\mathbf{P}$ & $\mathbf{S}$ & $\mathbf{T}$ & $\mathbf{W}$ & $\mathbf{Y}$ & $\mathbf{V}$ \\
\hline TNF & 8.2 & 6 & 3 & 3 & 1.7 & 5.6 & 6.9 & 7.3 & 1.7 & 5.2 & 12.9 & 3.4 & 0.9 & 4.3 & 6.4 & 8.6 & 4.3 & 0.9 & 3 & 6.9 \\
\hline TNFRSM 21 & 6.1 & 5.2 & 3.7 & 4.6 & 3.7 & 4.1 & 6 & 5.5 & 3.2 & 4.4 & 9.2 & 6 & 2 & 2.4 & 7.5 & 10.4 & 7.5 & 0.9 & 1.5 & 6.3 \\
\hline TNFRSM 6B & 10.3 & 10.3 & 2 & 2 & 7 & 4.7 & 6.3 & 7.7 & 2.7 & 1.3 & 11.7 & 0.7 & 0.7 & 3.3 & 9.7 & 5.7 & 6.3 & 1 & 1.3 & 5.3 \\
\hline TNFRSM18 & 9.4 & 9.4 & 0 & 3.5 & 10.2 & 5.5 & 4.3 & 14.5 & 2.7 & 0.4 & 5.5 & 2 & 1.2 & 2.4 & 11 & 7.84 & 5.1 & 2.7 & 0.4 & 2 \\
\hline TNFRSM 1A.1 & 4.4 & 5.9 & 3.7 & 4.6 & 6.6 & 3.3 & 6.6 & 6.6 & 2.2 & 2.9 & 12.7 & 4.4 & 1.1 & 3.1 & 8.1 & 7.9 & 6.8 & 1.1 & 2.9 & 5.1 \\
\hline TNFRSM 1A.2 & 5.5 & 6.3 & 3.7 & 4.3 & 5.8 & 3.5 & 6.9 & 5.8 & 1.4 & 2.6 & 12.7 & 4 & 1.2 & 3.7 & 8.4 & 7.8 & 7.5 & 1.4 & 2.6 & 4.9 \\
\hline TNFRSM1A .3 & 6 & 6.6 & 2 & 5 & 3.3 & 3.3 & 6.3 & 5.6 & 0.7 & 2.6 & 14.2 & 4.3 & 1.3 & 4 & 10.9 & 8.6 & 7 & 2 & 2.6 & 3.6 \\
\hline TNFR SM13.1 & 8.4 & 7.6 & 2.4 & 3.2 & 1.2 & 8 & 4.4 & 9.6 & 2.4 & 2.4 & 11.2 & 3.2 & 2.4 & 2.8 & 6.4 & 8.8 & 4 & 2 & 2.4 & 7.2 \\
\hline TNFR SM 13.2 & 8.5 & 8.1 & 2.6 & 3 & 1.3 & 8.1 & 4.7 & 10.3 & 1.7 & 2.1 & 11.2 & 2.6 & 2.6 & 3 & 6.4 & 8.5 & 3.8 & 2.1 & 2.6 & 6.8 \\
\hline TNFR SM 13.3 & 8.5 & 7.7 & 2.4 & 3.2 & 1.2 & 8.1 & 4.5 & 9.7 & 2.4 & 2.4 & 11.3 & 2.8 & 2.4 & 2.4 & 6.5 & 8.9 & 4 & 2 & 2.4 & 6.9
\end{tabular}

Where: $\mathrm{A}=$ Alanine, $\mathrm{R}=$ Arginine, $\mathrm{N}=$ Asparagine, $\mathrm{D}=$ Aspartic acid, $\mathrm{C}=$ Cysteine, $\mathrm{Q}=$ Glutamine, $\mathrm{E}=\mathrm{Glutamic}$ acid, $\mathrm{G}=$ Glycine, $\mathrm{H}=$ Histidine, $\mathrm{I}=$ Isoleucine, $\mathrm{L}=$ Leucine, $\mathrm{K}=$ Lysine, $\mathrm{M}=$ Methionine, $\mathrm{F}=$ Phenylalanine, $\mathrm{P}=\mathrm{Proline}$, $\mathrm{S}=$ Serine, $\mathrm{T}=$ Threonine, $\mathrm{W}=$ Tryptophan, $\mathrm{Y}=$ Tyrosine, $\mathrm{V}=$ Valine, $\mathrm{X}=$ Unspecified amino acid

Table 3. Physicochemical properties of different Tumor Necrosis Factors in Homo sapiens.

\begin{tabular}{|c|c|c|c|c|c|c|}
\hline PROTEIN & MW & pI & No. of $\mathbf{A A}$ & +ve AA & -ve AA & Instability index \\
\hline TNF & 25644.42 & 6.44 & 233 & 22 & 23 & 40.75 \\
\hline TNFRSM 21 & 71844.86 & 8.09 & 655 & 73 & 69 & 49.51 \\
\hline TNFRSM 6B & 32679.58 & 8.68 & 300 & 33 & 25 & 61.98 \\
\hline TNFRSM 18 & 26827.25 & 8.63 & 255 & 29 & 20 & 52.46 \\
\hline TNFRSM 1A. 1 & 50494.87 & 6.23 & 455 & 47 & 51 & 57.56 \\
\hline TNFRSM 1A.2 & 38651.26 & 6.03 & 347 & 36 & 39 & 59.79 \\
\hline TNFRSM 1A. 3 & 33675.71 & 6.21 & 302 & 33 & 34 & 64.07 \\
\hline TNFRSM 13.1 & 27433.31 & 9.67 & 250 & 27 & 19 & 61.63 \\
\hline TNFRSM 13.2 & 25678.26 & 9.62 & 234 & 25 & 18 & 63.33 \\
\hline TNFRSM 13.3 & 27058.83 & 9.58 & 247 & 26 & 19 & 62.72 \\
\hline
\end{tabular}


Studies have connected molecular weight with the composition of amino acids in proteins. There has been direct relation between molecular weight and amino acid composition [65]. This study also supports our results in which we have observed that among all Tumor necrosis Factors, TNFRSM21 has the highest molecular weight, i.e., 71844.86, and also has the highest composition of amino acids, i.e., 655 (Table 3). Another parameter called the Instability index was used for predicting the in vivo stability of Proteins by using their amino acid sequences [66]. The proteins having an Instability index less than 40 are considered stable, while proteins that have values more than 40 considered to be unstable. In our observations, according to the instability index, all the proteins have values more than 40, including TNF, i.e., 40.75 (Table 3); thus, all proteins are considered as unstable. The pI (Isoelectric point) is the $\mathrm{pH}$ of a solution at which the net charge of a protein becomes zero. At the Isoelectric point, all proteins are existed in the intensive form [67]. At a $\mathrm{pH}$ below their pI, i.e., less than 7 indicate that protein carries a net positive charge means proteins are acidic in nature and at $\mathrm{pH}$ values above their $\mathrm{pI}$ mean they have a net negative charge which shows proteins are basic in nature. According to the evaluated values of the isoelectric point from ProtParam tool TNF, TNFRSM1A.1, TNFRSM1A.2, TNFRSM 1A.3 was acidic in nature $(\mathrm{pH}<7)$, whereas TNFRSM 21, TNFRSM 6B, TNFRSM 18, TNFRSM 13.1, TNFRSM13.2, TNFRSM 13.3 were basic in nature $(\mathrm{pH}>7)$ (Table 3$)$. The $\mathrm{pI}$ plays a prominent role in the abstersion process as it signifies the $\mathrm{pH}$ level where protein solubility is minimal. Studies have shown that TNF is sensitive to their $\mathrm{pH}$ levels. The activity of TNF is predominant in acidic $\mathrm{pH}$, while its activity is decreased in basic or alkaline $\mathrm{pH}$ [68]. It has also been studied that expression of TNF is minimum in the presence of combined high doses of glutamine and arginine [69] while it is maximum in the presence of sulfur-containing amino acids, i.e., cysteine and methionine [70]. From our study, we have found that TNFRSM18 and TNFRSM 13.2 have the highest content of cysteine and methionine (Table 2).

\subsection{Secondary structure prediction.}

Prediction of the secondary structure of the protein was made by using Self Optimized Prediction Method with Alignment (SOPMA) tool [55]. SOPMA calculated the parameters such as percentage of alpha-helix, random coils, extended beta strands by homology methodology [71]. From SOPMA we calculated that TNFRSM 1A.3, TNF, TNFRSM6B, TNFRSM 13.3, and TNFRSM 21 has a high percentage of alpha-helix, i.e., 36.09\%, 31.33\%, $31.00 \%, 28.74 \%$, and $28.40 \%$, whereas TNFRSM 18 has the lowest percentage of alpha-helix, i.e., $15.29 \%$ (Table 4). We used the Protparam tool to calculate the percentage of amino acid in various proteins, which shows that TNFRSM 1A.3, TNF, TNFRSM6B, TNFRSM 13.3, and TNFRSM 21 has a high percentage of Leucine and Serine in the polypeptide chains, whereas TNFRSM 18 has a high percentage of Glycine (Table 2). Studies have shown that amino acids have a high propensity for forming secondary structures of protein. Amino acids such as alanine, leucine, methionine, glutamate, and lysine have high helix propensity, whereas glycine and proline have a poor tendency of forming helical structure [72]. Leucine and alanine have high helical propensity because of their successive repetition in helical structures [73]. These various studies also endorse our results, where the prevalence of the above-described amino acids accounts for appropriate secondary structures of a protein. 


\subsection{Homology modeling and validation.}

In our study, I-tasser was used for homology modeling. Five 3D models were derived for all TNF using I-tasser. Different bioinformatics tools were used to accredit the attributes of these models (Table 5). Overall Quality Factor or ERRAT which is a bioinformatics tool used to analyze the statistics between different atoms having non-bonded interactions [74]. I-tasser has been used to check the quality of models concerning an overall quality factor that checks the reliability of calculated models [75]. The high quality of generated models shows the highest values of quality factor [76]. The supposed range is greater than 50 for a high-quality model. In TNF of Homo sapiens TNFRSM 21, TNF, TNFRSM13.3, TNFRSM 1A.2, TNFRSM 13.1, TNFRSM 1A.3, TNFRSM 18, TNFRSM 13.2, TNFRSM 1A.1 and TNFRSM 6B has the highest Errat scores i.e 95.2\%, 88.88\%, 86.19\%, 82.68\%, 80.16\%, 78.91\%, 75.9\%, $75.66 \%, 74.58 \%$ and $55.51 \%$ (Table 5).

Table 4. Secondary structure percentages (\%) by SOPMA of TNF of Homo sapiens.

\begin{tabular}{l|c|c|c|c|c|c|c|c|c} 
Protein & $\begin{array}{c}\text { Alpha } \\
\text { helix }(\boldsymbol{\%})\end{array}$ & $\begin{array}{c}\mathbf{3 1 0} \text { helix } \\
(\boldsymbol{\%})\end{array}$ & $\begin{array}{c}\text { Pi helix } \\
(\boldsymbol{\%})\end{array}$ & $\begin{array}{c}\text { Beta bridge } \\
(\boldsymbol{\%})\end{array}$ & $\begin{array}{c}\text { Extended } \\
\text { strand (\%) }\end{array}$ & $\begin{array}{c}\text { Beta } \\
\text { turn }(\boldsymbol{\%})\end{array}$ & $\begin{array}{c}\text { Bend region } \\
(\boldsymbol{\%})\end{array}$ & $\begin{array}{c}\text { Random } \\
\text { coil }(\boldsymbol{\%})\end{array}$ & $\begin{array}{c}\text { Ambiguous } \\
\text { states }(\boldsymbol{\%})\end{array}$ \\
\hline TNF & 31.33 & 0.00 & 0.00 & 0.00 & 25.75 & 7.30 & 0.00 & 35.62 & 0.00 \\
\hline TNFRSM21 & 28.40 & 0.00 & 0.00 & 0.00 & 10.84 & 4.27 & 0.00 & 56.49 & 0.00 \\
\hline TNFRSM6B & 31.00 & 0.00 & 0.00 & 0.00 & 8.33 & 6.67 & 0.00 & 54.00 & 0.00 \\
\hline TNFRSM18 & 15.29 & 0.00 & 0.00 & 0.00 & 9.41 & 7.06 & 0.00 & 68.24 & 0.00 \\
\hline TNFRSM 1A. 1 & 26.87 & 0.00 & 0.00 & 0.00 & 11.87 & 4.18 & 0.00 & 57.14 & 0.00 \\
\hline TNFRSM 1A. 2 & 25.07 & 0.00 & 0.00 & 0.00 & 11.82 & 3.46 & 0.00 & 59.65 & 0.00 \\
\hline TNFRSM 1A. 3 & 36.09 & 0.00 & 0.00 & 0.00 & 6.62 & 5.63 & 0.00 & 51.66 & 0.00 \\
\hline TNFRSM 13.1 & 26.00 & 0.00 & 0.00 & 0.00 & 21.60 & 5.60 & 0.00 & 46.80 & 0.00 \\
\hline TNFRSM 13.2 & 27.78 & 0.00 & 0.00 & 0.00 & 24.36 & 5.13 & 0.00 & 42.70 & 0.00 \\
\hline TNNRSM 13.3 & 28.74 & 0.00 & 0.00 & 0.00 & 22.67 & 4.86 & 0.00 & 43.72 & 0.00
\end{tabular}

As per the calculated data, all TNF models showed the value of quality factor greater than 50, which shows that all Errat models are appropriate for further proteomic studies. To evaluate protein structures, 3D- verify score has been used to compare the structural environment of protein with a referential environment of amino acids [59]. In TNF of Homo sapiens 3D- verify percentage of the best model were 93.13\%, 56.03\%, 90.67\%,95.29\%, $86.81 \%, 82.71 \%, 98.68 \%, 99.6 \%, 95.3 \%$ and $92.71 \%$ for TNF, TNFRSM21, TNFRSM6B, TNFRSM18, TNFRSM1A.1, TNFRSM1A.2, TNFRSM1A.3, TNFRSM13.1, TNFRSM13.2 and TNFRSM13.3 (Table 5). PROCHECK, another 3D-validation tool, checks the stereochemistry of a protein structure, producing several postscript plots analyzing its overall and residue-by-residue geometry using Ramachandran Plot. This plot has three regions residues in the allowed region, most favored regions, and residues in disallowed regions. In pursuance of PROCHECK, if the most favored regions have over $90 \%$ amino acids, then the model must be considered a good quality model. RAMPAGE provides a detailed structural evaluation that shows the number of residues in allowed and outlier regions and the number of residues in favored regions. In Homo sapiens, TNF, TNFRSM21, TNFRSM6B, TNFRSM18, TNFRSM1A.1, TNFRSM1A.2, TNFRSM1A.3, TNFRSM13.1, TNFRSM13.2 and TNFRSM13.3 has highest value of PROCHECK score, i.e., 67.8\%, 60.9\%, 54.1\%, 46.3\%, $65.0 \%, 57.4 \%, 61.6 \%, 65.4 \%, 65.8 \%$ and $65.4 \%$ (Table 5). In case of best model of TNF the RAMPAGE score, i.e., the number of residues in favoured regions were $75.3 \%, 77.6 \%, 63.1 \%$, $56.1 \%, 75.1 \%, 67.8 \%, 68.0 \%, 71.0 \%, 70.3 \%$ and $74.3 \%$ for TNF, TNFRSM21, TNFRSM6B, TNFRSM18, TNFRSM1A.1, TNFRSM1A.2, TNFRSM1A.3, TNFRSM13.1, TNFRSM13.2 and TNFRSM13.3 (Table 5). A high value of generated models indicates the advanced quality of all these models. 
Table 5. Validation scores of different 3D models of Homo sapiens generated via I- TASSER.

\begin{tabular}{l|c|c|c|c} 
PROTEIN & 3D VERIFY $(\boldsymbol{\%})$ & ERRAT $(\boldsymbol{\%})$ & PROCHECK $(\boldsymbol{\%})$ & RAMPAGE $(\boldsymbol{\%})$ \\
\hline TNF & 93.13 & 88.88 & 67.8 & 75.3 \\
\hline TNFRSM 21 & 56.03 & 95.2 & 60.9 & 77.6 \\
\hline TNFRSM 6B & 90.67 & 55.51 & 54.1 & 63.1 \\
\hline TNFRSM 18 & 95.29 & 75.9 & 46.3 & 56.1 \\
\hline TNFRSM 1A.1 & 86.81 & 74.58 & 65.0 & 75.1 \\
\hline TNFRSM 1A.2 & 82.71 & 82.68 & 57.4 & 67.8 \\
\hline TNFRSM 1A.3 & 98.68 & 78.91 & 61.6 & 71.0 \\
\hline TNFRSM 13.1 & 99.6 & 80.16 & 65.4 & 70.3 \\
\hline TNFRSM 13.2 & 95.3 & 75.66 & 65.8 & 74.3
\end{tabular}

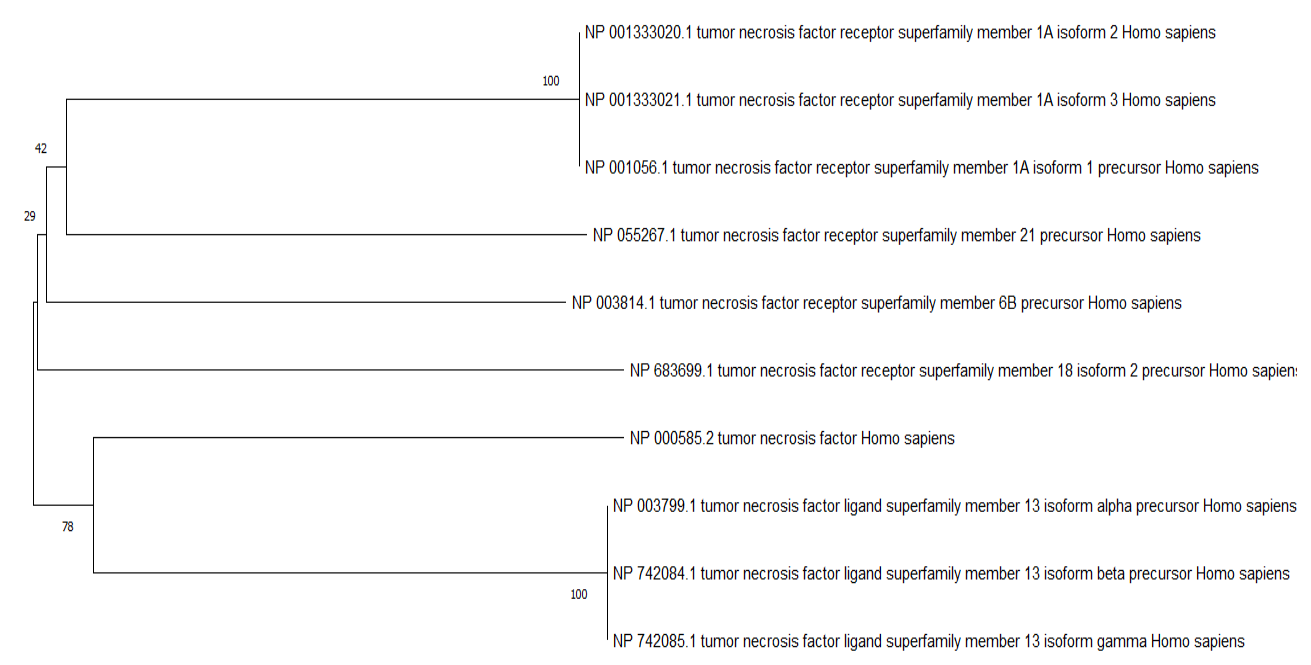

Figure 1. Phylogenetic analysis of TNF proteins of Homo sapiens.

\subsection{Phylogenetic analysis.}

To determine an evolutionary relationship between various Tumor Necrosis Factor proteins of Homo sapiens, the MEGA7 bioinformatics tool was used $[62,77,78]$. The sequence was aligned using ClustalW [79-81].

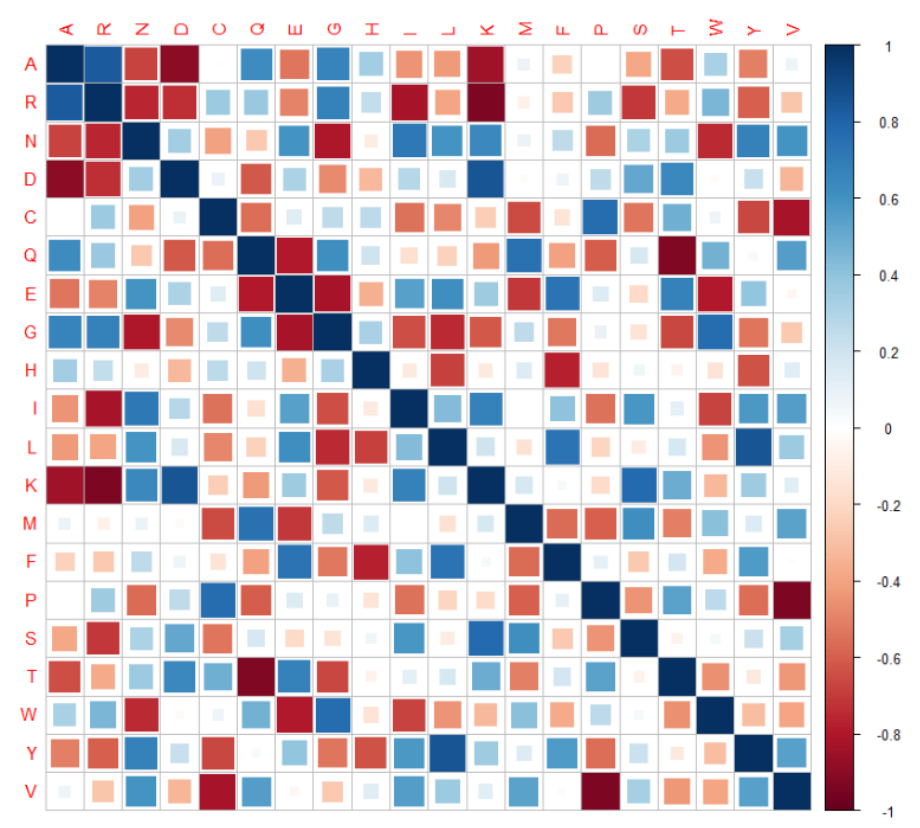

Figure 2. Pearson correlation of different TNF in Homo sapiens. 
The bootstrap value of 60 was taken as the threshold. Phylogenetic tree reveals that out of all ten proteins, TNFRSM 13 isoform $\alpha$, TNFRSM 13 isoform $\beta$, TNFRSM 13 isoform $\gamma$ were evolved earlier [82]. The proteins TNFRSM 1A isoform 2, TNFRSM 1A isoform 3, TNFRSM 1A isoform 1 were recently evolved. TNFRSM 1A isoform 2, TNFRSM 1A isoform 3, TNFRSM 1A isoform 1, and TNFRSM 21 are evolved from a common ancestor TNFRSM 6B. The proteins TNFRSM 13 isoform $\alpha$, TNFRSM 13 isoform $\beta$, TNFRSM 13 isoform $\gamma$, and protein TNF are evolved from the common ancestor TNFRSM 18 isoform 2 precursors. Proteins TNFRSM 13 isoform $\alpha$, TNFRSM 13 isoform $\beta$, TNFRSM 13 isoform $\gamma$ are distantly related from proteins TNFRSM 1A isoform 2, TNFRSM 1A isoform 3, TNFRSM 1A isoform 1 (Fig. 1).

\subsection{Pearson correlation.}

By using Pearson's correlation [83] for different amino acids, it has been found that in the case of Homo sapiens, lysine, isoleucine, glutamine, arginine, lysine, leucine, and asparagine are positively correlated to aspartic acid, tyrosine, methionine, alanine, serine, phenylalanine, and isoleucine. While arginine, alanine, glutamine, proline, threonine, and glycine are negatively correlated to lysine, aspartic acid, isoleucine, valine, cysteine, asparagine, and lysine (Fig. 2).

\subsection{Multivariate technique.}

From multivariate technique [84-88] and heat map cluster analysis of Homo sapiens, it has been found that- Proteins TNF, TNF ligand SM 13 isoform beta precursor, TNF ligand SM 13 isoform gamma precursor, and TNF ligand SM 13 alpha precursor have the same amino acid composition of alanine, serine, proline, asparagine, tryptophan, cysteine, threonine, and valine. Proteins TNFRSM 18 isoform 2 precursors, TNFRSM 21 precursor, TNFRSM 1A isoform 3 precursor, and TNF have different amino acids (Fig.3).

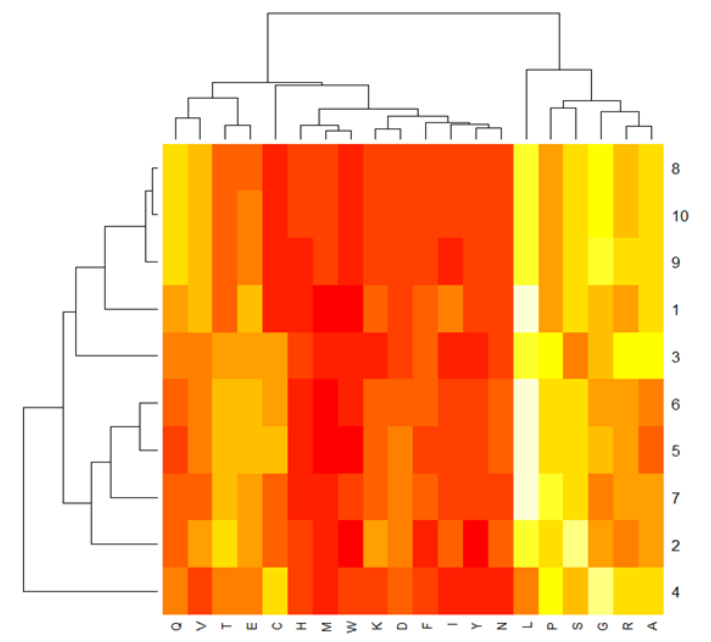

Figure 3. Heat map showing an amino acid composition of different TNF in Homo sapiens.

\section{Conclusions}

Our studies revealed in silico structure prediction and assessment of TNF proteins. According to parameter, i.e., instability index, all the TNF proteins were found to be unstable. The assortment of acidic and basic proteins was done by considering the isoelectric point. The 
prevalence of alpha-helical structure was predicted in the secondary structure of these proteins. For all ten TNF, a total of five 3D- models were generated, out of which the most predicted structure was evaluated through different validatory scores, i.e., ERRAT\%, 3D-VERIFY\%, RAMPAGE\%, and PROCHECK\%. This study explored the basic characteristics and structures of TNF, which will lay the foundation for protein docking and molecular modeling of these proteins for future studies.

\section{Funding}

This research received no external funding.

\section{Acknowledgments}

The authors are thankful to the Head, Department of Zoology, DAV University, Jalandhar, and Head, Department of Biotechnology, Maharishi Markandeshwar (Deemed to be University) for her/his incessant moral support.

\section{Conflicts of Interest}

The authors declare no conflict of interest.

\section{References}

1. Idriss, H.T.; Naismith, J.H. TNF $\alpha$ and the TNF receptor superfamily: Structure, function relationship (s). Microbiol. Res. Technol. 2000, 50, 184-95, https://doi.org/10.1002/1097-0029(20000801)50:3<184::AIDJEMT2>3.0.CO;2-H.

2. Hira, K.; Begum, A.S. Methods for evaluation of TNF- $\alpha$ inhibition effect. In: The TNF Superfamily. Humana, New York, NY. 2021;pp. 271-9, https://doi.org/10.1007/978-1-0716-1130-2_21.

3. Elif Burcu, A.; Muhammet, A.; Mustafa Kemal, S. A Label-free Electrochemical Immunosensor for Highly Sensitive Detection of TNF $\alpha$, Based on Star Polymer-modified disposable ITO Electrode. Curr. Pharma.l Analysis 2021, 17, 450-459,https://doi.org/10.2174/1573412916999200409111759.

4. Wang, D.; He, L.; Zhang, X. -308G/A polymorphism of tumor necrosis factor alpha (TNF- $\alpha$ ) gene and metabolic syndrome susceptibility: a meta-analysis. Sci. Rep. 2021, 11, 1-8, https://doi.org/10.1038/s41598021-83321-X.

5. Huang, J.; Wang, L.; Yu, C.; Fu, Z.; Liu, C.; Wu, G.; Guo, L.; Guo, X.; Chen, S.; Liu, X.; Wang, J. Development of a robust bioassay of monoclonal antibodies and biosimilars against TNF- $\alpha$ by NF- $\mathrm{BB}-$ inducible lentiviral reporter gene. Int.l Immunopharmacol. 2021, 93, https://doi.org/10.1016/j.intimp.2021.107418.

6. Younis, N.N.; Mohamed, H.E.; Shaheen, M.A.; Abdelghafour, A.M.; Hammad, S.K. Inactivation of Wnt/ $\beta$ catenin/renin angiotensin axis by tumor necrosis factor-alpha inhibitor, infliximab, ameliorates CKD induced in rats. Biochem. Pharmacol. 2021, 185, https://doi.org/10.1016/j.bcp.2021.114426.

7. Choksi, S.; Choudhary, G.; Liu, Z.G. Transition from TNF-induced inflammation to death signaling.In: The TNF Superfamily. Humana, New York, NY. 2021;pp. 73-80, https://doi.org/10.1007/978-1-0716-1130-2_5.

8. Zhang, L.; Yao, C.H. The physiological role of tumor necrosis factor in human immunity and its potential implications in spinal manipulative therapy: A narrative literature review. J. Chiro. Med. 2016, 15, 190-6, https://doi.org/10.1016/j.jcm.2016.04.016.

9. Sinaga, B.Y.M.; Amir, Z. Tumor Necrosis Factor-alpha -308G/A Polymorphism Associated with Increased Risk for Pulmonary Tuberculosis in Medan City, Indonesia. Mac. J. Med. Sci. 2021, 9, 711, https://doi.org/10.3889/oamjms.2021.5559.

10. Hamad, N.; Alzoubi, K.H.; Swedan, S.F.; Khabour, O.F.; El-Salem, K. Association between tumor necrosis factor alpha and lymphotoxin alpha gene polymorphisms and migraine occurrence among Jordanians. Neurol. Sci. 2021,1-6, https://doi.org/10.1007/s10072-020-04967-5.

11. Ghareeb, D.; Abdelazem, A.S.; Hussein, E.M.; Al-Karamany, A.S. Association of TNF- $\alpha-308 \mathrm{G}>\mathrm{A}$ (rs1800629) polymorphism with susceptibility of metabolic syndrome. J. Diabetes Metabol Disord. 2021, 1-7, https://doi.org/10.1007/s40200-021-00732-3.

12. Özkan, M.; Günay, N.; Sener, E.F.; Karcıglu, Ö.; Tahtasakal, R.; Dal, F.; Günay, N.E.; Demiryürek, A.T. Variants in TNF and NOS3 (eNOS) genes associated with sepsis in adult patients. J. Gene Med. 2021, 23, https://doi.org/10.1002/jgm.3323. 
13. Carswell, E.A.; Old, L.J.; Kassel, R.L.; Green, S.; Fiore, N.; Williamson, B. An endotoxin-induced serum factor that causes necrosis of tumors. Proc. Natl. Acad. Sci. USA. 1975, 72, 3666-70, https://doi.org/10.1073/pnas.72.9.3666.

14. Scott, K.A.; Arnott, C.H.; Robinson, S.C.; Moore, R.J.; Thompson, R.G.; Marshall, J.F.; Balkwill, F.R. TNFa regulates epithelial expression of MMP-9 and integrin avb6 during tumour promotion: A role for TNF-a in keratinocyte migration. Oncl. 2004, 23, 6954-66, https://doi.org/10.1038/sj.onc.1207915.

15. Ferreira, S.H.; Lorenzetti, B.B.; Cunha, F.Q.; Poole, S. Bradykininrelease of TNF- $\alpha$ plays a key role in the development of inflammatory hyperalgesia. Agen. Act.1993, 38, C7-9, https://doi.org/10.1007/BF01991120.

16. Gong, K; Guo, G; Beckley, N; Zhang, Y; Yang, X; Sharma, M; Habib, A.A. Tumor necrosis factor in lung cancer: Complex roles in biology and resistance to treatment. Neoplasia 2021,23,189-196, https://doi.org/10.1016/j.neo.2020.12.006

17. Tuli, H.S.; Bhatia, G.K.; Sood, S.; Debnath, P.; Upadhyay, S.K.; Kumar, P.; Nene, A.G.; Kumar, J.; Punia, S.; Talwar, S.; Yadav, P. In silico evaluation of harmane \& palmarin as $\alpha$-Glucosidase inhibitors: Hope for the discovery of antihyperglycemic compounds. Int. J. Pharma. Res. 2020, 12, 1331-6, https://doi.org/10.31838/ijpr/2020.SP1.176.

18. Hsu, H.; Huang, J.; Shu, H.B.; Baichwal, V.; Goeddel, D.V. TNF-dependent recruitment of the protein kinase RIP to the TNF receptor-1 signaling complex. Immunol. 1996, 4, 387-96, https://doi.org/10.1016/S10747613(00)80252-6.

19. Palanki, M.S.; Erdman, P.E.; Gayo-Fung, L.M.; Shevlin, G.I.; Sullivan, R.W.; Goldman, M.E.; Ransone, L.J.; Bennett, B.L.; Manning, A.M.; Suto, M.J. Inhibitors of NF- $\kappa$ B and AP-1 gene expression: SAR Studies on the pyrimidine portion of 2-Chloro-4-trifluoromethylpyrimidine-5-[N-(3 ', 5 '-bis (trifluoromethyl) phenyl) carboxamide]. J. Med. Chem. 2000, 43, 3995-4004, https://doi.org/10.1021/jm0001626.

20. Sudhakar,C.; Nagabhushana, A.; Jain, N.; Swarup, G. NF-кB mediates tumor necrosis factor $\alpha$-induced expression of optineurin, a negative regulator of NF-kB. Plos One. 2009, 4, https://doi.org/10.1371/journal.pone.0005114.

21. Psarras, A; Antanaviciute, A; Alase, A; Carr, I; Wittmann, M; Emery, P; Tsokos, G.C; Vital, E.M. TNF- $\alpha$ Regulates Human Plasmacytoid Dendritic Cells by Suppressing IFN- $\alpha$ Production and Enhancing T Cell Activation. J. Immunol. 2021, 206, 785-796, https://doi.org/10.4049/jimmunol.1901358.

22. Zhou, Y; Fan, R; Botchway, B.O; Zhang, Y; Liu, X. Infliximab Can Improve Traumatic Brain Injury by Suppressing the Tumor Necrosis Factor Alpha Pathway. Mol. Neurobiol. 2021, 1-9, https://doi.org/10.1007/s12035-021-02293-1.

23. Zhang, L.; Liu, R.; Luan, Y.Y.; Yao, Y.M. Tumor necrosis factor- $\alpha$ induced protein 8: Pathophysiology, clinical significance, and regulatory mechanism. Int. J. Biol. Sci. 2018, 14, https://doi.org/10.7150/ijbs.23268.

24. Niture, S.; Dong, X.; Arthur, E.; Chimeh, U.; Niture, S.S.; Zheng, W.; Kumar, D. Oncogenic role of tumor necrosis factor $\alpha$-induced protein 8 (TNFAIP8). Cell. 2019, 8, https://doi.org/10.3390/cells8010009.

25. Ishii, H.; Kaneko, S.; Yanai, K.; Aomatsu, A.; Hirai, K.; Ookawara, S.; Ishibashi, K.; Morishita, Y. MicroRNAs in podocyte injury in diabetic nephropathy. Front. Gene. 2020, 11, https://doi.org/10.3389/fgene.2020.00993.

26. Lorenzo-Vizcaya, A.; Isenberg, D.A. The use of anti-TNF-alpha therapies for patients with systemic lupus erythematosus. Where are we now? Exp. Opin. Biol. Ther. 2021, https://doi.org/10.1080/14712598.2021.1853096.

27. Pattanaik, K.P; Ganguli, G; Naik, S.K; Sonawane, A. Mycobacterium tuberculosis EsxL induces TNF- $\alpha$

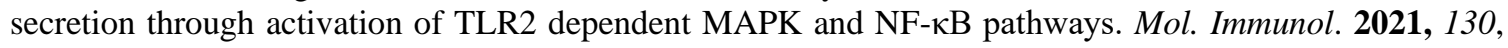
133-141, https://doi.org/10.1016/j.molimm.2020.11.020.

28. Akash, M.S.; Rehman, K.; Liaqat, A. Tumor necrosis factor alpha: Role in development of insulin resistance and pathogenesis of type 2 diabetes mellitus. J. Cell Biochem. 2018, 119, 105-10, https://doi.org/10.1002/jcb.26174.

29. Dhiman, S.; Kumar, I.; Palia, P.; Jamwal, S.; Kumar, P. TNF- $\alpha$ : A Benificial or Harmful Pathogenic Cytokine in Cardiovascular System. J. Drug Deliv. Ther. 2021, 11, 114-120, https://doi.org/10.22270/jddt.v11i1.4507

30. El-Salem, K.; Al-Mistarehi, A.-H.; Hanan, K.; Alham, A.-S.; Yassin, A. Serum Tumor Necrosis FactorAlpha Levels Correlate with Cognitive Function Scales Scores in Multiple Sclerosis Patients. Multiple Scler. Related Disord. 2021, 47, https://doi.org/10.1016/j.msard.2020.102621.

31. Dong, Y.; Fischer, R.; Naudé, P.J.; Maier, O.; Nyakas, C.; Duffey, M.; Van der Zee, E.A.; Dekens, D.; Douwenga, W.; Herrmann, A.; Guenzi, E. Essential protective role of tumor necrosis factor receptor 2 in neurodegeneration. Proc. Natl. Acad. Sci. 2016, 113, 12304-9, https://doi.org/10.1073/pnas.1605195113.

32. Behboodi, N.; Farazestanian, M.; Rastgar-Moghadam, A.; Mehramiz, M.; Karimi, E.; Rajabian, M.; Rahmani, F.; Khorrami, S.; Jafarian, A.; Sharifi-Sistani, N.; Ferns, G.A.; Avan, A.; Hasanzadeh, M. Association of a variant in the tumor necrosis factor alpha gene with risk of cervical cancer. Mol. Biol. Rep. 2021, 48, 1433-1437, https://doi.org/10.1007/s11033-021-06185-4.

33. O'Reilly, M.L.; Mironets, E.; Shapiro, T.M.; Crowther, K.; Collyer, E.; Bethea, J.R.; Tom, V.J. Pharmacological Inhibition of Soluble Tumor Necrosis Factor-Alpha Two Weeks after High Thoracic Spinal 
Cord Injury Does Not Affect Sympathetic Hyperreflexia. J. Neurotr. 2021, https://doi.org/10.1089/neu.2020.7504.

34. Mercogliano, M.F.; Bruni, S.; Mauro, F.; Elizalde, P.V.; Schillaci, R. Harnessing Tumor Necrosis Factor alpha to achieve effective cancer immunotherapy. Cancers 2021, 13, https://doi.org/10.3390/cancers13030564.

35. Miguel, M.G.; da Silva, C.I.; Farah, L.; Castro Braga, F.; Figueiredo, A.C. Effect of essential oils on the release of TNF- $\alpha$ and CCL2 by LPS-stimulated THP-1 cells. Plant. 2021, 10, https://doi.org/10.3390/plants10010050.

36. Meza, K.; Biswas, S.; Zhu, Y.-S.; Gajjar, A.; Perelstein, E.; Kumar, J.; Akchurin, O. Tumor necrosis factoralpha is associated with mineral bone disorder and growth impairment in children with chronic kidney disease. Pediat. Nephrol. 2021,1-9, https://doi.org/10.1007/s00467-020-04846-3.

37. Chakraborty, C.; Agoramoorthy, G. Comparative bioinformatic analysis of the conserved domains, amino acid residues, and binding grooves of tumor necrosis factor. Med. Glas. (Zenica).2014, 11, 1-6.

38. Jayaram, A.; Deer, E.; Amaral, L.M.; Campbell, N.; Vaka, V.R.; Cunningham, M.; Ibrahim, T.; Cornelius, D.C.; LaMarca, B.B. The role of tumor necrosis factor in triggering activation of natural killer cell, multiorgan mitochondrial dysfunction and hypertension during pregnancy. Preg. Hypert. 2021, 24, 65-72, https://doi.org/10.1016/j.preghy.2021.02.006.

39. Cheng, D.; Liang, R.; Huang, B.; Hou, J.; Yin, J.; Zhao, T.; Zhou, L.; Wu, R.; Qian, Y.; Wang, F. Tumor necrosis factor- $\alpha$ blockade ameliorates diabetic nephropathy in rats. Clin. Kidney J. 2021, 14, 301-308, https://doi.org/10.1093/ckj/sfz137.

40. Saravi, B.; Li, Z.; Pfannkuche, J.; Wystrach, L.; Häckel, S.; E Albers, C.; Grad, S.; Alini, M.; Richards, R.G.; Lang, C.; Südkamp, N. Angiotensin II type 1 receptor antagonist losartan inhibits TNF- $\alpha$-Induced inflammation and degeneration processes in human nucleus pulposus cells. Appl. Sci. 2021, 11, https://doi.org/10.3390/app11010417.

41. Balzar, S.; Chu, H.W.; Strand, M.; Wenzel, S. Relationship of Small Airway Chymase-Positive Mast Cells and Lung Function in Severe Asthma. Amer. J. Resp. Crit. Care Med. 2005, 171, 431-439, https://doi.org/10.1164/rccm.200407-949OC.

42. Taylor, P.C. Pharmacology of TNF blockade in rheumatoid arthritis and other chronic inflammatory diseases. Curr.Opin. Pharmacol. 2010, 10, 308-315, https://doi.org/10.1016/j.coph.2010.01.005.

43. Eck, M.J.; Sprang, S.R. The structure of tumor necrosis factor-alpha at $2.6 \mathrm{~A}$ resolution. Implications for receptor binding. J. Biol. Chem. 1989, 264, 17595-17605, https://doi.org/10.2210/pdb1tnf/pdb.

44. Jones, E.Y.; Stuart, D.I.; Walker, N.P.C. Structure of tumour necrosis factor. Nature 1989, 338, 225-228, https://doi.org/10.1038/338225a0.

45. Wajant, H.; Mühlenbeck, F.; Scheurich, P. Identification of a TRAF (TNF Receptor-Associated Factor) Gene in Caenorhabditis elegans. J. Mol. Evol. 1998, 47, 656-662, https://doi.org/10.1007/p100006423.

46. Reja, S.I.; Sharma, N.; Gupta, M.; Bajaj, P.; Bhalla, V.; Parihar, R.D.; Ohri, P.; Kaur, G.; Kumar, M. A Highly Selective Fluorescent Probe for Detection of Hydrogen Sulfide in Living Systems: In Vitro and in Vivo Applications. Chem. Europ. J. 2017, 23, 9872-9878, https://doi.org/10.1002/chem.201701124.

47. Parihar, R.D.; Kaur, S.S.; Ohri, P. Morphometric variations in Distolabrellus veechi (Nematoda: Rhabditidae) collected from different localities in Punjab, India. Indian J. Nematol. 2016,46,193-197.

48. Sharma, P.; Gupta, N.; Kaur, S.; Kaur, S.; Ohri, P.; Parihar, R.D.; Kumar, M. Imaging of lysosomal activity using naphthalimide-benzimidazole based fluorescent probe in living cells. Actuators B. Chem. 2019, 286, 451-459, https://doi.org/10.1016/j.snb.2019.01.134.

49. Parihar, R.D.; Singh, I.; Verma, V.; Sohal, S.K.; Kesavan, A.K.; Ohri, P. Biocontrol potential of Distolabrellus veechi isolate KPI (Nemata: Rhabditida) against cotton cutworm, Spodoptera litura (Lepidoptera: Noctuidae). Indian J. Nematol.2019, 49,71-82.

50. Gupta, N.; Kaur, T.; Bhalla, V.; Parihar, R.D.; Ohri, P.; Kaur, G.; Kumar, M. A naphthalimide-based solid state luminescent probe for ratiometric detection of aluminum ions: in vitro and in vivo applications. Chem. Comm. 2017, 53, 12646-12649, https://doi.org/10.1039/C7CC07996F.

51. Parihar, R.D.; Singh, I.; Sohal, S.K.; Kesavan, A.K.; Ohri, P. Molecular characterization and study of abiotic soil parameters to understand the natural habitat preference of entomopathogenic nematode Distolabrellus veechi isolates. Indian J. Nematol. 2020, 49, 146-155.

52. Garg, V.K.; Avashthi, H.; Tiwari, A.; Jain, P.A.; Ramkete, P.W.; Kayastha, A.M.; Singh, V.K. MFPPI Multi FASTA ProtParam interface. Bioinformation 2016, 12, 74-77, https://doi.org/10.6026/97320630012074.

53. Geourjon, C.; Deléage, G. SOPMA: Significant improvements in protein secondary structure prediction by consensus prediction from multiple alignments. Bioinformatics 1995, 11, 681-684, https://doi.org/10.1093/bioinformatics/11.6.681.

54. Zhang, Y. I-TASSER server for protein 3D structure prediction. BMC Bioinformatics 2008, 9, https://doi.org/10.1186/1471-2105-9-40.

55. Heider, D.; Barnekow, A. DNA watermarks: A proof of concept. BMC Mol. Biol. 2008, 9, https://doi.org/10.1186/1471-2199-9-40. 
56. Eisenberg, D.; Lüthy, R.; Bowie, J.U. VERIFY3D: assessment of protein models with three-dimensional profiles. Methods Enzymol.Academic Press 1997, 277, 396-404, https://doi.org/10.1016/S00766879(97)77022-8.

57. Lüthy, R.; Bowie, J.U.; Eisenberg, D. Assessment of protein models with three-dimensional profiles. Nature 1992, 356, 83-85, https://doi.org/10.1038/356083a0.

58. Colovos, C.; Yeates, T.O. Verification of protein structures: Patterns of nonbonded atomic interactions. Prot. Sci. 1993, 2, 1511-1519, https://doi.org/10.1002/pro.5560020916.

59. Lovell, S.C.; Davis, I.W.; Arendall Iii, W.B.; de Bakker, P.I.W.; Word, J.M.; Prisant, M.G.; Richardson, J.S.; Richardson, D.C. Structure validation by $\mathrm{C} \alpha$ geometry: $\phi, \psi$ and $\mathrm{C} \beta$ deviation. Prot. Struct., Func.Bioinform. 2003, 50, 437-450, https://doi.org/10.1002/prot.10286.

60. Laskowski, R.A.; MacArthur, M.W.; Moss, D.S.; Thornton, J.M. PROCHECK: a program to check the stereochemical quality of protein structures. J. Appl. Crystallogr. 1993, 26, 283-291, https://doi.org/10.1107/S0021889892009944.

61. Laskowski, R.A.; MacArthur, M.W.; Moss, D.S.; Thornton, J.M.; SFCHECK: a unified set of procedures for evaluating the quality of macromolecular structure-factor data and their agreement with the atomic model. J. Appl.Crystallogr. 1993, 26,283-291, https://doi.org/10.1107/s0907444998006684.

62. Kumar, S.; Stecher, G.; Tamura, K. MEGA7: Molecular Evolutionary Genetics Analysis Version 7.0 for Bigger Datasets. Mol. Biol. Evol. 2016, 33, 1870-1874, https://doi.org/10.1093/molbev/msw054.

63. Kumar, S.; Upadhyay, S.K. Pathogenesis of Flavobacterium colunare in fish of fresh water riverine ecosystem from eastern region of Uttar Pradesh, India. Int. J. Rec. Scient. Res. 2016, 7, 13676-9.

64. Dhiman, U.; Parihar, R.D.; Rana, S.; Upadhyay, S.K.; Kumar, V. Comparative In Silico Analysis of Randomly Selected Heat Shock Proteins in Caenorhabditiselegans and Photorhabdustemperata. Biointerface Res. Appl. Chem. 2021, 4, 11418-30, https://doi.org/10.33263/BRIAC114.1141811430.

65. Guan, Y.; Zhu, Q.; Huang, D.; Zhao, S.; Lo, L.J.; Peng, J. An equation to estimate the difference between theoretically predicted and SDS PAGE-displayed molecular weights for an acidic peptide. Sci. Rep. 2015, 5, 1-1, https://doi.org/10.1038/srep13370.

66. Guruprasad, K.; Reddy, B.V.B.; Pandit, M.W. Correlation between stability of a protein and its dipeptide composition: a novel approach for predicting in vivo stability of a protein from its primary sequence. Prot.Engig., Des. Select. 1990, 4, 155-161, https://doi.org/10.1093/protein/4.2.155.

67. Sivakumar, K.; Balaji, S.; Gangaradhakrishnan. In silico characterization of antifreeze proteins using computational tools and servers. J. Chem. Sci. 2007, 119, 571-579, https://doi.org/10.1007/s12039-0070072-y.

68. Bidani, A.; Wang, C.Z.; Saggi, S.J.; Heming, T.A. Evidence for pH sensitivity of Tumor Necrosis Factor- $\alpha$ release by alveolar macrophages. Lung 1998, 176, 111-121, https://doi.org/10.1007/PL00007593.

69. Lecleire, S.p.; Hassan, A.; Marion-Letellier, R.; Antonietti, M.; Savoye, G.; Bôle-Feysot, C.; Lerebours, E.; Ducrotté, P.; Déchelotte, P.; Coëffier, M.S. Combined glutamine and arginine decrease proinflammatory cytokine production by biopsies from crohn's patients in association with changes in Nuclear Factor- $\kappa \mathrm{B}$ and p38 mitogen-activated protein kinase pathways. J. Nutr. 2008, 138, 2481-2486, https://doi.org/10.3945/jn.108.099127.

70. Hunter, E.A.L.; Grimble, R.F. Cysteine and methionine supplementation modulate the effect of tumor necrosis factor $\alpha$ on protein synthesis, glutathione and zinc concentration of liver and lung in rats fed a low protein diet. J. Nutr. 1994, 124, 2319-2328, https://doi.org/10.1093/jn/124.12.2319.

71. Singh, N.; Upadhyay, S.; Jaiswar, A.; Mishra, N. In silico analysis of protein. J. Bioinform. Genom. Proteom. 2016, 1 .

72. Nick Pace, C.; Martin Scholtz, J. A helix propensity scale based on experimental studies of peptides and proteins. Biophys $J$ 1998, 75, 422-427, https://doi.org/10.1016/S0006-3495(98)77529-0.

73. Chou, P.Y.; Fasman, G.D. Empirical predictions of protein conformation. Annu. Rev. Biochem.1978, 47 ,251-276, https://doi.org/10.1146/annurev.bi.47.070178.001343.

74. Bowie, J.U.; Luthy, R.; Eisenberg, D. A method to identify protein sequences that fold into a known threedimensional structure. Science 1991, 253, 164-170, https://doi.org/10.1126/science.1853201.

75. Pandey, V.P.; Singh, S.; Jaiswal, N.; Awasthi, M.; Pandey, B.; Dwivedi, U.N. Papaya fruit ripening: ROS metabolism, gene cloning, characterization and molecular docking of peroxidase. J. Mol. Catal.s B: Enzym. 2013, 98, 98-105, https://doi.org/10.1016/j.molcatb.2013.10.005.

76. Messaoudi, A.; Belguith, H.; Ben Hamida, J. Homology modeling and virtual screening approaches to identify potent inhibitors of VEB-1 $\beta$-lactamase. Theor. Biol. Med. Model. 2013, 10, https://doi.org/10.1186/1742-4682-10-22.

77. Bhat, A.H.; Chaubey, A.K.; Upadhyay, S.K. Morphotaxometric and molecular validation of entomopathogenic nematode, Steinernema abbasi (Rhabditida: Steinernematidae) with mucronate processes in adults of second generations off subhumid region, Uttar Pradesh, India. World J. Pharm. Pharma. Sci. 2016, 5, 1558-79.

78. Istkhar; Chaubey, A.K.; Upadhyay, S.K. Molecular phylogeny of three variable size juvenile isolates of Steinernema abbasi (Rhabditida: Steinernematidae) from the western part of Uttar Pradesh, India by the application of conserved genes sequence analyses. Int. J. Glob. Sci. Res. 2016, 3, 302-12. 
79. Upadhyay, S.K. Morphotaxometry and molecular heterogeneity of Sturdynema multiembryonata gen. et sp.n. (Spiruroidea: Gnathostomatinae) of fresh water garfish, Xenentodon cancilla from the Gangetic riverine ecosystem in northern India with a revised key to genera of Gnathostomatinae. Species. 2017, 18, 1-13.

80. Upadhyay, S.K. Molecular barcode analysis and phylogeny of parasitic helminthes: A laboratory manual. Res. J. Rec. Sci. 2018, 7, 22-7.

81. Upadhyay, S.K.; Babita; Panwar, P.; Singh, M.; Singh, R. Linking of DNA sequences and molecular heterogeniety with phylogeny for morphotaxonomic validation of parasites: A modern reliable technique in taxonomy. In: Parasitology Taxonomy and Bioecology (ed. Upadhyay, S.K.). Write and Print Publ. New Delhi 2019, 1, 134-54.

82. Tuli, H.S.; Mittal, S.; Aggarwal, D.; Parashar, G.; Parashar, N.C.; Upadhyay, S.K.;Barwal, T.S.; Jain, A.; Kaur, G.; Salva, R.; Sak, K.; Kumar, M.; Varol., M.; Iqubal, A.; Sharma, A.K. Path of silibinin from diet to medicine: A dietary polyphenolic flavonoid having potential anti-cancer therapeutic significance. Sem. Cancer Biol. 2020, https://doi.org/10.1016/j.semcancer.2020.09.014.

83. Upadhay, S.K. Transmission dynamics and environmental influence on food borne parasitic helminthes of the Gangetic plains and central west coast of India. UnPubl. D.Phil Thesis University of Allahabad. 2012, $1,1-400$.

84. Jaiswal, N.; Upadhyay, S.K.; Malhotra, A.; Malhotra, S.K. Multifactorial etiology of infections by larvae of Eustrongylides tubifex (Nematoda: Dioctophymidae) in silver whiting of the central west coast of India at Goa. Asian J. Biol. Sci. 2013, 6, 21-39, https://doi.org/10.3923/ajbs.2013.21.39.

85. Jaiswal, N.; Upadhyay, S.K.; Malhotra, A.; Malhotra, S.K. Ecological morphotaxometry of trematodes of garfish (Teleostomi: Belonidae) from Gangetic riverine ecosystem in India. III. Principal Component Analysis for hydrobiological correlates to dynamics of infections by Cephalogonimus yamunii (Upadhyay, Jaiswal, Malhotra and Malhotra, 2012). J. Parasit. Dis. 2014, 38, 153-62, https://doi.org/10.1007/s12639012-0200-6.

86. Upadhyay, S.K.; Yadav, D.; Pathak, R.K. The impact of water quality on the population distribution pattern of cephalogonimid trematodes Cephalogonimus yamunii in fresh water fish Heteropneustes fossilis at Allahabad, Uttar Pradesh. J. Kalash Sci. 2015, 3, 11-7.

87. Upadhyay, S.K. Environmental impact on helminth parasites of fresh water garfish from river Yamuna at Allahabad, Uttar Pradesh, India. Proc. Zool. Soc. India. 2017, 16, 63-75.

88. Upadhyay, S.K.; Singh, R. Polyfactorial etiology on demography of parasitic allocreodoidean trematodes in the Gangetic ecosystem. AASCIT Amer. J. Biomed. Sci. Engg. 2018, 4, 17-23. 